\section{WHERE TO NEXT?}

The GRIPP program is innovative and experimental and over the next few years we hope to learn more about how to improve research and practice links. The next issue of the NSW Public Health Bulletin will highlight examples of how the principles of GRIPP are being used in public health programs in NSW. The issue has been guest edited by Philip Davies from the Government Chief Social Researcher's Office, Prime Minister's Strategy Unit, Cabinet Office, London, and Shelley Bowen, GRIPP Program Director at The Sax Institute.

The Sax Institute was formerly known as the Institute for Health Research. The Institute changed its name in 2005 to better reflect its role in building research partnerships for better health. The Institute is named after Dr Sidney Sax, one of Australia's first health planners and a major leader in public health, health services reform, and establishing research in these areas.

For more information about any of the initiatives described here, visit The Sax Institute website, www.saxinstitute.org.au, or contact Danielle Campbell via danielle.campbell@ saxinstitute.org.au.

\section{REFERENCES}

1. Innvaer S, Vist G, Trommald M, Oxman A. Health policymakers' perceptions of their use of evidence: a systematic review. J Health Serv Res Policy 2002; 7(4): 239-44.

2. Elliott H, Popay J. How are policy makers using evidence? Models of research utilisation and local NHS policy making. J Epidemiol Community Health 2000; 54(6): 461-8.

3. Jacobson N, Butterill D, Goering P. Organizational factors that influence university-based researchers' engagement in knowledge transfer activities. Sci Commun 2004; 25(3): 246-59.

4. Lin, V. From public health research to health promotion policy: on the 10 major contradictions. Soz Praventivmed 2004; 49(3):179-84.

5. Bowen S, Zwi A. Pathways to "evidence-informed" policy and practice: A framework for action. PLoS Med 2005; 2(7): e166.

6. Walter I, Davies H, Nutley S. Increasing research impact through partnerships: evidence from outside health care. $J$ Health Serv Res Policy 2003; 8(2 suppl.): 58-61. 웡

\title{
THE BANGKOK CHARTER FOR HEALTH PROMOTION IN A GLOBALIZED WORLD: WHAT IS IT ALL ABOUT?
}

\section{Chris Rissel \\ Health Promotion Service \\ Sydney South West Area Health Service}

On August 11, 2005, in Bangkok, Thailand, the delegates of the Sixth World Health Organization (WHO) Global Health Promotion Conference endorsed a statement known as the Bangkok Charter for Health Promotion in a Globalized World. ${ }^{1}$ This article briefly describes the background to the Bangkok Charter, summarises the main components and highlights some of the issues arising from its preparation.

\section{BACKGROUND}

The Ottawa Charter of 1986, a product of the first WHO global health promotion conference, was a significant milestone in the evolution of health promotion. ${ }^{2}$ It established the principles and strategies of health promotion and has effectively defined health promotion since then. The Charter is still highly relevant today.

Since 1986 there have been four other global health promotion conferences. These were held in: Adelaide (1988 - theme of healthy public policy) ${ }^{3}$, Sunsvall,
Sweden (1991 — theme of supportive environments conducive to health and sustainable development $)^{4}$, Jakarta, Indonesia (1997-focus on partnerships) ${ }^{5}$ and Mexico City (2000-focus on confirming political support for health promotion). ${ }^{6}$ Each of these meetings generated a Declaration or Statement, but none of these products had the same dramatic reach and impact as the Ottawa Charter.

The Sixth WHO Global Health Promotion Conference (7-11 August, 2005) endorsed the Bangkok Charter for Health Promotion in a Globalized World. Almost 20 years since the Ottawa Charter, the world is a different place, politically and economically. Transport and communication developments have allowed processes of globalization to rapidly change the contexts and environment of people in most countries of the world. Global economies and trade agreements mean that the same products are now available worldwide in a way never seen before. These changes require a new public health response and new ways of working.

\section{HOW THE CHARTER WAS DEVELOPED}

The Bangkok Charter was the product of a complex 
process of consultation and discussion, culminating in its modification and final endorsement at the Sixth Global Conference. The WHO regional offices and the International Union of Health Education and Promotion held consultations on earlier draft versions of the Charter prior to the Bangkok conference. Also prior to the conference a draft had been posted on the WHO website and this had attracted comment from additional stakeholders. At the Bangkok Conference delegates participated in 29 separate technical discussions grouped around four major themes: sustainable actions, health-friendly globalization, partners, and new context. Recommendations from each group contributed to a complete revision of the Charter during the conference. Further input from delegates was then taken into account on the last evening of the conference by a 'finalisation' or writing group that prepared the final version, which was endorsed on August 11, 2005.

The Bangkok Charter for Health Promotion is not intended to replace the Ottawa Charter, but rather to complement and build upon it and the recommendations of the subsequent global health promotion conferences. It is intended as a framework rather than a detailed action plan, and does not seek to cover all aspects of health promotion. It briefly summaries the global context of health promotion before specifying the major action areas.

The Bangkok Charter for Health Promotion states that:

To make further advances in health all sectors and settings must act to:

- Advocate for health based on human rights and solidarity

- Invest in sustainable policies, actions and infrastructure to address the determinants of health

- Build capacity for policy development, leadership, health promotion practice, knowledge transfer and research, and health literacy

- Regulate and legislate to ensure a high level of protection from harm and enable equal opportunity for health well being for all people

- Partner and build alliances with public, private, nongovernmental organizations and civil society to create sustainable actions. ${ }^{1}$

Addressing all of the Millennium Development Goals is identified as a critical entry point for health promotion. ${ }^{7}$ The eight Millennium Development Goals were proclaimed in 2000 as goals that all United Nations agencies (including WHO) and member states (including Australia) should address, with the intention of reaching these goals by 2015 . The goals seek to:

1. Eradicate extreme poverty and hunger

2. Achieve universal primary education

3. Promote gender equality and empower women

4. Reduce child mortality
5. Improve maternal health

6. Combat HIV/AIDS, malaria and other diseases

7. Ensure environmental sustainability

8. Develop a global partnership for development.

Four commitments to health for all are stated in the Bangkok Charter. These are:

- to make the promotion of health central to the global development agenda

- to make it a core responsibility for all of government

- to make it a key focus of communities and civil society

- to make the promotion of health a requirement for good corporate practices.

A paragraph of text expands upon each of these points and the Charter ends with a global pledge by the conference participants.

\section{ISSUES}

Prior to the conference, a number of comments on the draft Charter were circulated by various stakeholders and, in particular, by the People's Health Movement. Their comments included comment on the neutral tone of the document towards globalization, with the suggestion that the document should explicitly identify the serious negative impact of globalization on health. While they acknowledged that some developing countries benefit from globalization, they proposed that elements of globalization such as transnational property and land tenure concentration, largescale social exclusion, privatization of public resources, and the loss of human rights, have exacerbated health inequalities. Endorsement of public-private partnerships also received criticism, succinctly summarized by the comment that 'public-private partnerships should not be promoted but should be regulated'. A greater emphasis on human rights was called for, with the suggestion that there be specific reference to Article 12 of the International Covenant on Economic, Social and Cultural Rights.

During the conference, many issues familiar to health promotion and public health practitioners arose. These included the need for political will to support health promotion and not simply treatment services, the need for whole-of-government approaches, the need to work with partners and the need to address the social determinants of health-'the causes of the causes of poor health', as keynote speaker Michael Marmot put it.

The wide-ranging discussions of 700 conference delegates, the breadth of the challenges facing health promotion, and the editorial input of a diverse committee, make the writing of a document like the Bangkok Charter very difficult. Part of the difficulty in writing it revolves around identifying the audience for such a document. Is the Charter for health promotion people or for all stakeholders from various sectors that impact upon health? A narrower target group makes tailoring the document easier. 
The Bangkok Charter was written for a very broad audience, for all potential stakeholders rather than primarily for people with a particular interest in health promotion. It seeks a number of commitments from these other stakeholders. However, contrary to health promotion principles, very few of these stakeholders participated in the process of developing the Charter or were invited as delegates to the Conference. This weakens the capacity of the Charter to have a direct influence on them.

The general endorsement of the Bangkok Charter highlights the strategic issues that health promotion needs to address in a global context. Supporting documentation or further direction is needed as to what health promotion practice should do to address globalization issues, the social determinants of health and 'the underlying causes of poverty, poor health and inequalities'. Workforce development is one area needing attention, as new skills will be necessary to effect change in a more 'global' world. For example, the recent signing of the bilateral Free Trade Agreement between Australia and the United States is likely to have important public health consequences for Australia, but (with some notable exceptions) there was relatively little discussion within the public health community here, let alone as part of the general public discourse. The majority of public health and health promotion experts lack skills in foreign policy, not to mention the political skills that are necessary to influence what is largely a political process. Re-orienting health services towards prevention was one of the five strategies of the Ottawa Charter and is still very relevant.

Whether the Bangkok Charter is the best it can be or not, it is the product of the attention of a great many people. It is too early to tell what influence it will have but at the very least it should alert us to the importance of paying more attention to the negative aspects of globalization and to addressing the fundamental social determinants of health.

A discussion of the Bangkok Charter appears in a series of Editorials in the December 2005 issue of the Health Promotion Journal of Australia (volume 16 , number 3)..$^{8-10}$

\section{REFERENCES}

1. World Health Organization and the Thai Ministry of Health. Bangkok charter for health promotion in a globalized world. Sixth Global Conference on Health Promotion. Policy and partnership for action: addressing the determinants of health. Bangkok, Thailand, 7-11 August, 2005. Available at www. who.int/healthpromotion/conferences/. Accessed 5 January 2006.

2. World Health Organization and the Canadian Public Health Association. The Ottawa charter for health promotion. First International Health Promotion Conference, Ottawa, Canada, 17-21 November, 1986. Available at www.who.int/ healthpromotion/conferences/. Accessed 5 January 2006.

3. World Health Organization. The Adelaide recommendations on healthy public policy. The Second International Conference on Health Promotion, Adelaide, Australia, 5-9 April, 1988. Available at www.who.int/healthpromotion/conferences/. Accessed 5 January 2006.

4. World Health Organization. Sundsvall statement on supportive environments for health. The Third International Conference on Health Promotion, Sundsvall, Sweden, 9-15 June, 1991. Available at www.who.int/healthpromotion/conferences/. Accessed 5 January 2006.

5. World Health Organization. Jakarta declaration. The Fourth International Conference on Health Promotion: New players for a new era-leading health promotion in the $21^{\text {st }}$ century. Jakarta, Indonesia, July 21-25, 1997. Available at www. who.int/healthpromotion/conferences/. Accessed 5 January 2006.

6. World Health Organization. Mexico ministerial statement for the promotion of health. The Fifth Global Conference on Health Promotion-Health Promotion: Bridging the equity gap, Mexico City, Mexico, June 5, 2000. Available at www. who.int/healthpromotion/conferences/ . Accessed 5 January 2006.

7. United Nations. Millenium development goals. At www. un.org/millenniumgoals/. Accessed 5 January 2006.

8. Ritchie J. The Bangkok Charter: impressions of its birth. Health Promot J Austr 2005; 16(3): 167-8.

9. World Health Organization. The Bangkok Charter for health promotion in a globalized world. Health Promot J Austr 2005; 16(3): 168-171.

10. Health Promotioin Unit, World Health Organization. A charter to achieve health for all. Health Promot J Austr 2005; 16(3): 171-2. 용 